\title{
Neues Mittel für Diarrhö-betonten Reizdarm
}

\author{
Viele der Hoffnungen auf neue Medikamente zur Behandlung des Reizdarmsyndroms haben \\ sich nicht erfüllt. Gelingt mit dem nun in den USA zugelassenen Eluxadolin der Durchbruch?
}

\begin{abstract}
Zahlreiche Medikamente zur Behandlung des Reizdarmsyndroms wurden in den letzten Jahren wegen Nebenwirkungen zurückgezogen oder aus der Erstattungsfähigkeit herausgenommen. Manche wurden gar trotz bestehender Zulassung selektiv vom deutschen Markt zurückgezogen, was für alle Beteiligten unbefriedigend ist. Nun wurde in den USA ein neues Mittel zugelassen.

Eluxadolin ist ein Vertreter einer neuen Substanzklasse und wirkt als Agonist am $\mu$-Opioidrezeptor (MOR) und als Antagonist am $\delta$-Opioidrezeptor (DOR). Die MOR-Aktivität, die ähnlich wie bei Loperamid auf die Peripherie be-
\end{abstract}

schränkt ist, verlangsamt gerade in Stresssituationen die gastrointestinale Motilität und reduziert die Sekretion. Die DOR-Wirkung verstärkt die Motilitätsreduktion.

In den Phase-III-Studien wurde Eluxadolin bei Diarrhö-betontem Reizdarmsyndrom zweimal täglich oral eingenommen. Der primäre Endpunkt, eine Verbesserung des SymptomenScores bei gleichzeitiger Normalisierung der Stuhlkonsistenz, wurde nach 12 Wochen von 29,6\% der mit Eluxadolin und 16,2\% der mit Placebo behandelten Patienten erreicht. Schon in der ersten Therapiewoche war ein Effekt erkennbar.
- Garnok-Jones K. Eluxadoline: First global approval. Drugs. 2015;75:1305-10

\section{KOMMENTAR}

Es ist erfreulich, dass trotz der Rückschläge weiterhin Arzneimittel in der Indikation entwickelt werden. Nun brauchen wir dringend Erfahrungen mit dem Einsatz von Eluxadolin außerhalb von klinischen Studien. Die aktuelle Einschränkung der Zulassungsbehörde FDA, dass Eluxadolin nur als kontrollierte Substanz einsetzbar ist, lässt aufhorchen. Man muss hoffen, dass nicht zentrale MORvermittelte Nebenwirkungen zu dieser Vorgabe geführt haben, denn dann wäre ein breiter Einsatz des Mittels fraglich.

Prof. Dr. med. M. Storr

\section{Gleichzeitiges Auftreten von primärer und sekundärer Syphilis}
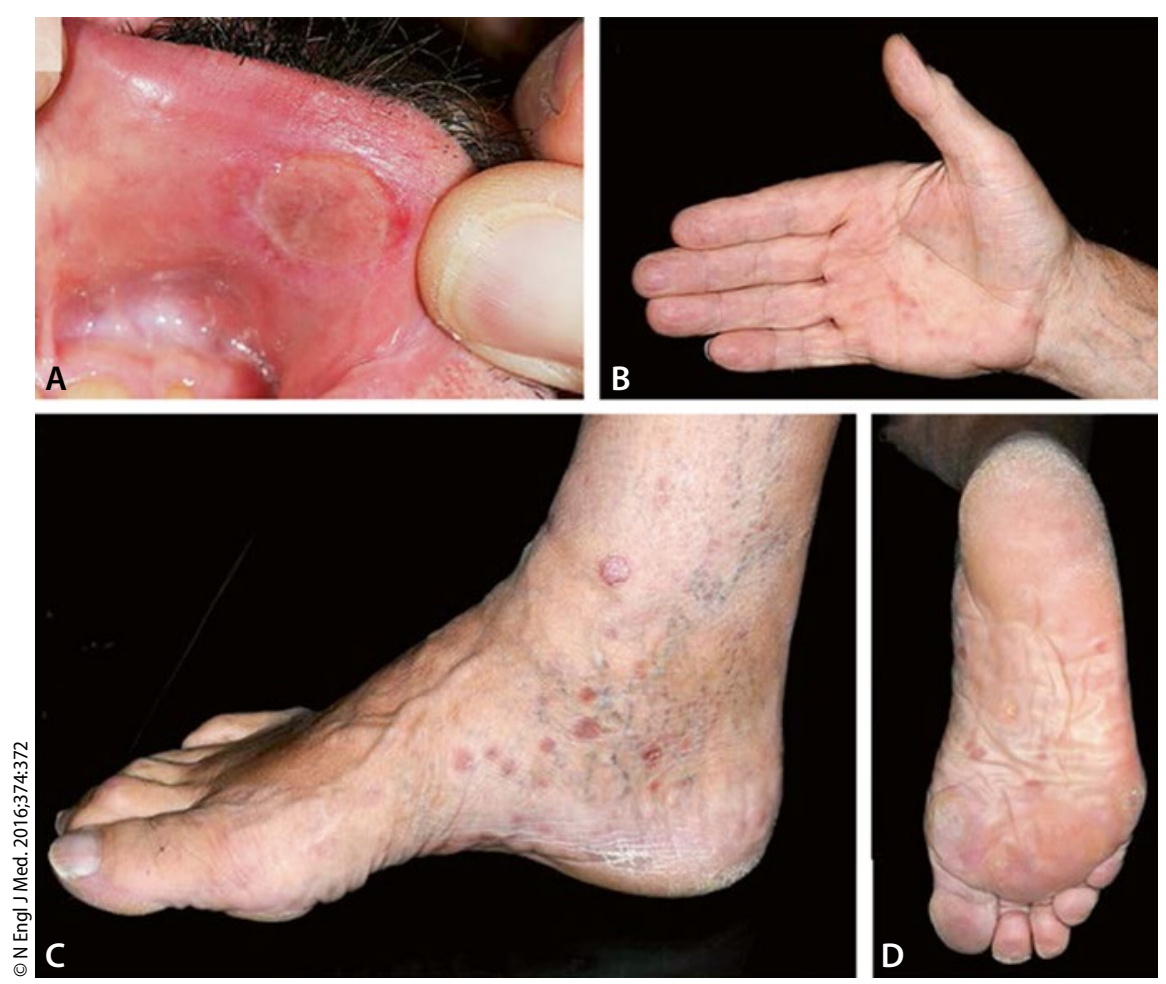

Erosion an der Innenseite der Oberlippe (A), schuppende Plaques an Handinnenflächen (B), Füßen (C) und Fußsohlen (D).
Ein 68-jähriger Mann hatte seit sechs Wochen eine schmerzlose Erosion an der Innenseite der Oberlippe (Abb. A). An Händen und Füßen zeigten sich zusätzlich schuppende Plaques (Abb. B, $C, D)$, die seit etwa einem Jahr kamen und gingen. In der Labordiagnostik zeigten sich ein positiver TPPA-Assay mit einem Titer von 1:2.560 und ein positiver VDRL-Test mit einem Titer von 1:8. Serologische Untersuchungen auf HIV und Hepatitis verliefen negativ. Der Immunoblot war positiv für Lues-spezifische IgM und IgG. Die histologische Untersuchung von Biopsien aus der Oberlippenläsion und den Plaques ergab eine Ulzeration und eine psoriasiforme Hyperplasie. Es fanden sich massenhaft CD79Apositive Plasmazellen und Spirochäten. Unter der Diagnose einer gleichzeitigen primären und sekundären Syphilis wurde der Mann mit Penicillin G Benzathin behandelt. Binnen zwei Monaten kam es zu einer Normalisierung.

Ein solches gleichzeitiges Auftreten ist ungewöhnlich, aber prinzipiell möglich, da keine Immunität für eine Zweitinfektion besteht.

Prof. Dr. med. H. S. FüeßI

- Schön MP, Bertsch HP (michael.schoen@med.uni-goettingen.de). Primary and secondary syphilis. N Engl J Med. 2016;374:372 